\title{
Conformerism, enantiomorphism and double catemer motifs in para-substituted nostoclide analogues
}

\author{
Róbson Ricardo Teixeira a, b, Luiz Claudio Almeida Barbosa ${ }^{\text {a, b, * }}$, Isabel Valero Antolinez a , \\ Rodrigo de Souza Corrêa ${ }^{\text {d, Felipe Terra Martins }}{ }^{\text {e, }}{ }^{* *}$, Antônio Carlos Doriguetto ${ }^{\text {c }}{ }^{* * *}$ \\ ${ }^{a}$ Chemistry Department, Universidade Federal de Minas Gerais, CEP 3409-5720 Belo Horizonte, MG, Brazil \\ b Chemistry Department, Universidade Federal de Viçosa, CEP 36570-900 Viçosa, MG, Brazil \\ ${ }^{\mathrm{c}}$ Institute of Chemistry, Federal University of Alfenas, CEP 37130-000 Alfenas, MG, Brazil \\ d Chemistry Department, Federal University of OuroPreto, CEP 35400-000 OuroPreto, MG, Brazil \\ e Chemical Institute, Federal University of Goiás, CEP 74001-970 Goiânia, GO, Brazil
}

\section{A R T I C L E I N F O}

\section{Article history:}

Received 9 October 2015

Received in revised form 29 October 2015

Accepted 30 October 2015

Available online 10 November 2015

\section{Keywords:}

Nostoclides

Butenolides

Gama-lactones

Gama-alkylidenebutenolides

Crystal structure

\begin{abstract}
A B S T R A C T
We have here elucidated the crystal structures of five nostoclide analogues. A common feature in all compounds is a substituent at the para-position of the benzylidene group. Compounds with either bromine (3) or hydroxyl (4) as para-substituent crystallizes with $Z^{\prime}=2$ as result of conformerism. It was also observed that $Z^{\prime}>1$ in the compound with a para-dimethylamino substituent (1). However, its four crystallographically independent molecules are conformationally similar. They are not related by crystallographic symmetry due to the offset packing of their $\mathrm{C}-\mathrm{H} \cdots \mathrm{O}=\mathrm{C}$ nonclassical hydrogen bonded double chains. This compound (1) has also crystallized in a chiral space group ( $\left.\mathrm{P} 2_{1}\right)$ despite the lack of a stereocenter. Such enantiomorphism phenomenon is related to the presence of only one of the two mirror benzyl conformations with phenyl ring at the equatorial position opposite the lactone oxygen atom. The molecular mean plane of nostoclide analogues has been featured by high level of planarity, except in the brominated compound where two twisted conformations occurred due to rotations on the single bond axis into benzylidene group. The benzyl conformation has been the greatest difference between the two crystallographically independent molecules of the para-hydroxylated compound (4). The crystal packing of the compounds is marked by double catemer motif assembled through $\mathrm{C}-\mathrm{H} \cdots \mathrm{O}=$ $\mathrm{C}$ non-classical hydrogen bonds, although $\mathrm{C}-\mathrm{H} \cdots \pi$ interactions do play an important role in stabilizing the crystal packing of some compounds of the series.
\end{abstract}

๑) 2015 Elsevier B.V. All rights reserved.

\section{Introduction}

The exploitation of marine species as source of natural products has been rewarding. A plethora of compounds of various complexities has been isolated from marine microorganisms and phytoplankton, green, brown and red algae, sponges, cnidarians, bryozons, among others $[1,2]$. These natural compounds have been

\footnotetext{
* Corresponding author. Chemistry Department, Universidade Federal de Minas Gerais, CEP 3409-5720 Belo Horizonte, MG, Brazil.

** Corresponding author. Chemical Institute, Federal University of Goiás, CEP 74001-970 Goiânia, GO, Brazil.

*** Corresponding author. Institute of Chemistry, Federal University of Alfenas, CEP 37130-000 Alfenas, MG, Brazil.

E-mail addresses: lcab@ufmg.br (L.C.A. Barbosa), felipeterramartins@gmail.com (F.T. Martins), doriguetto@unifal-mg.edu.br (A.C. Doriguetto).
}

considered important sources for the search and development of new pharmaceuticals [3-8] and agrochemicals [9]. Besides, the chemical novelty associated with those compounds has inspired organic chemists. As a consequence, several marine natural products have been targeted for total syntheses [10-16].

The nostoclides (I) and (II) (Fig. 1) are marine natural products produced by a cyanobacterium (Nostoc sp.) symbiont partner within lichen Peltigera canina. These compounds possess a $\gamma$-benzylidene functionality and belong to the class of substances known as $\gamma$-alkylidenebutenolides $[17,18]$.

These nostoclides displayed moderate cytotoxic effects against the mouse neuroblastoma cell lines Neuro-2aCCL and KB CCL 17 [19]. Taking into account that $P$. canina cultures are not usually contaminated with microorganisms, it has been suggested that these chlorinated compounds may be allelopathic agents.

We have been involved in the preparation and biological 


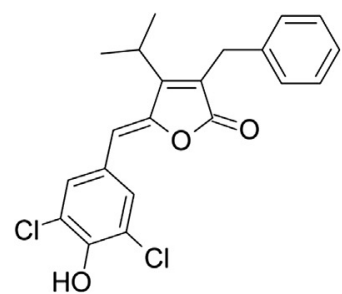

Nostoclide I<smiles>CC(C)C1=C(Cc2ccccc2)C(=O)OC1=Cc1ccc(O)c(Cl)c1</smiles>

Nostoclide II

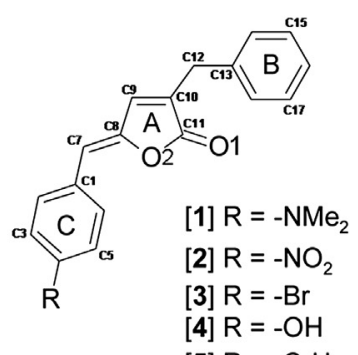

[5] $\mathrm{R}=-\mathrm{C}_{6} \mathrm{H}_{5}$

Fig. 1. Structures of nostoclides I and II and synthetic analogues [1-5] with ring and atom labeling scheme. The atom labeling of R is shown in Fig. 2 .

evaluation of several nostoclide analogues [20]. It has been demonstrated that these analogues, at different degrees, are capable of interfering with photosynthetic electron transport [21-25]. In addition, we have conducted investigations on the crystal structures of nostoclide analogues [26-28]. Aiming at contributing to further understand in detail the structures of such compounds, we describe in this paper our results concerning the crystal structure of nostoclide analogues bearing benzylidene appendages functionalized at para position.

\section{Experimental}

\subsection{Synthesis and preparation of crystalline samples}

By using the vinylogous aldol reaction between appropriate aldehydes and furan-based silyloxydiene synthon generated from 3benzyl-furan-2(5H)-one as the key step [29-31], compounds $\mathbf{1}$ to $\mathbf{5}$ (Fig. 2) were prepared in yields ranging from $33 \%$ to $91 \%$ [22].

The identities of nostoclide analogues $\mathbf{1}$ to $\mathbf{5}$ were confirmed upon full spectroscopic (one and two-dimensional NMR and IR) as well as mass spectrometric analyses [22]. Crystals of compounds $\mathbf{1}$ to $\mathbf{5}$ were obtained by gently warming each compound in hexane, followed by dropwise addition of dichloromethane until the solid was completely dissolved. The resulting solution was left undisturbed at room temperature. After approximately $24 \mathrm{~h}$, crystals suitable for X-ray analyses were formed. They were separated, washed with cold hexane, and dried.

\subsection{Single-crystal X-ray diffraction}

Prism-shaped single crystals of substances $\mathbf{1}$ to $\mathbf{5}$ were selected and mounted on the $\kappa$-goniostat of an Enraf-Nonius Kappa-CCD diffractometer. Room temperature diffraction intensities were collected using graphite-monochromated $\mathrm{MoK} \alpha$ X-ray beam through $\varphi-\omega$ scans and $\kappa$ offset [32]. The X-ray diffraction frames were recorded using the program COLLECT [33], and reduction and scaling of the raw dataset were performed with HKL DenzoScalepack [34].

The structures were solved by direct methods with SHELXS-97 [35]. The models were refined by the full-matrix least squares method on $F^{2}$ with SHELXL-97 [35], with anisotropic thermal parameters for non-hydrogen atoms. The hydrogen atoms were
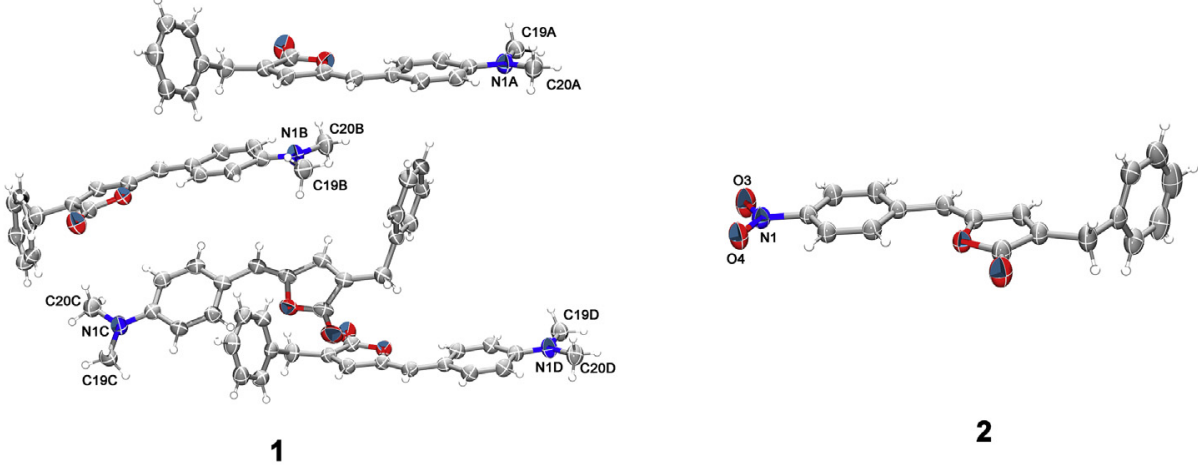

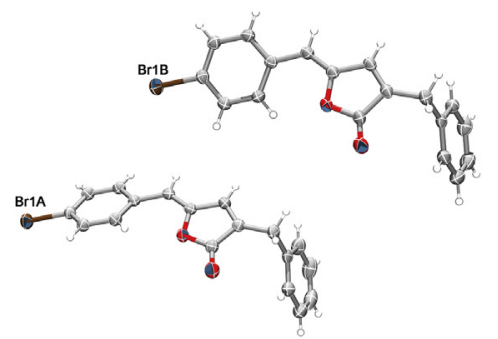

3

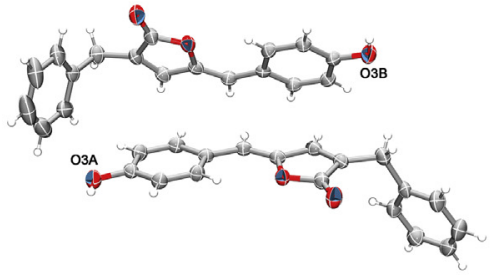

4

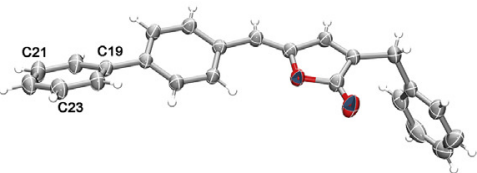

5

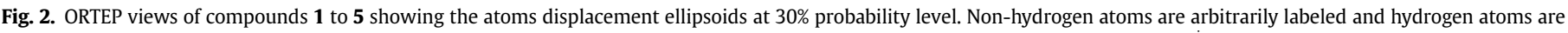
shown as spheres of arbitrary radii. Atom labeling scheme for nostoclide framework common to all compounds can be found in Fig. 1 i Symmetry code: $\mathrm{x},-\mathrm{y}+0.5, \mathrm{z}$. 
placed in idealized positions after their identification in the difference Fourier map. Then, they were refined with fixed individual isotropic displacement parameters $\left[\mathrm{U}_{\mathrm{iso}}(\mathrm{H})=1.2 \mathrm{U}_{\mathrm{eq}}\left(\mathrm{C}_{s p}^{2}\right.\right.$ or $\mathrm{C}_{s p}^{3}$ in methylene groups) or $1.5 \mathrm{U}_{\mathrm{eq}}\left(\mathrm{C}_{s p}^{3}\right.$ in methyl groups or $\left.\left.\mathrm{O}\right)\right]$ using a riding model with bond lengths of $0.82 \AA(\mathrm{O}-\mathrm{H}), 0.86 \AA(\mathrm{N}-\mathrm{H})$, $0.93 \AA\left(C_{s p}^{2}-\mathrm{H}\right), 0.97 \AA\left(\mathrm{C}_{s p}^{3}-\mathrm{H}\right.$ in methylene groups $)$ or $0.96 \AA$ $\left(\mathrm{C}_{s p}^{3}-\mathrm{H}\right.$ in methyl groups). A summary of crystal data and refinement statistics is given in Table 1.

The programs MERCURY [36] and ORTEP-3 [37] were used within the WinGX [38] software package to generate artworks. After the refinements had been completed, the molecular structures of all compounds were checked with MOGUL [39] tool derived from the Cambridge Structural Database (CSD [40], version 5.36 of November 2014). Crystallographic data for the structural analysis of the compounds herein discussed have been deposited at the Cambridge Crystallographic Data Centre, 12 Union Road, CambridgeCB2 $1 \mathrm{EZ}$, UK, and are available on request quoting the deposition numbers showed in Table 1.

\section{Results and discussion}

The compounds $\mathbf{1}$ to $\mathbf{5}$ are functionalized at para position of the $C$ aromatic ring (see Fig. 1 for ring labeling). The exocyclic double bond of all substances presents $Z$ configuration, a similar feature displayed in eight out of nine nostoclide analogues previously reported [27,28]. In addition, since analogues $\mathbf{1}$ to $\mathbf{5}$ present hydrogen atoms in the ortho positions of the $\mathrm{C}$ rings, a non-classical intramolecular hydrogen bond ( $\mathrm{C} 6-\mathrm{H} 6 \cdots \mathrm{O} 2)$ is present in their structures (Fig. 2).

Compound 1 crystallizes in the non-centrosymmetric monoclinic space group $\mathrm{P} 2{ }_{1}$ with four crystallographically independent molecules in its asymmetric unit (AU) as shown in Fig. 2 together with the chosen $\mathrm{AU}$ of the other compounds herein described. The four molecules in the $A U$ of $\mathbf{1}$ are remarkably similar from a conformational point of view, as can be seen in Fig. 3. The highest root mean square deviation (RMSD) for the non-hydrogen atoms is

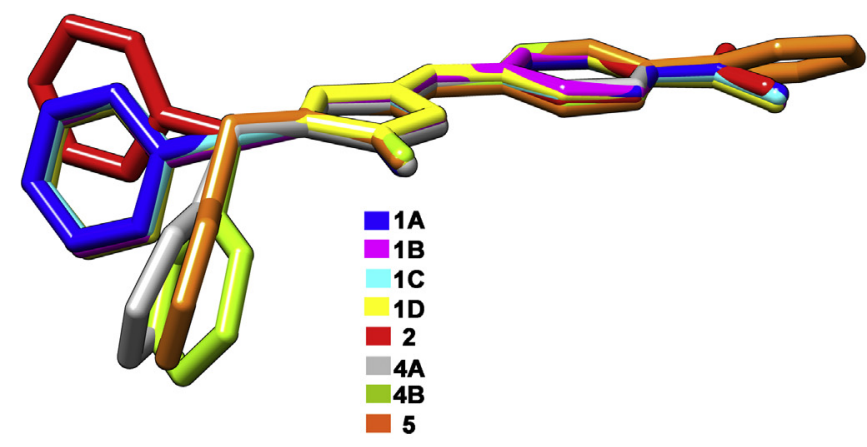

(a)

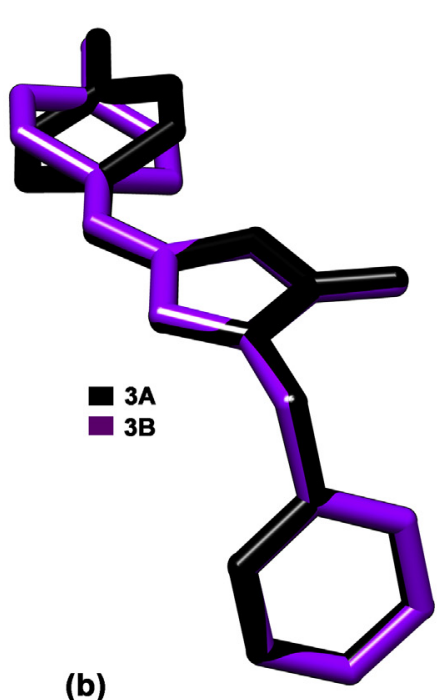

Fig. 3. Superposition of crystallographically independent molecules present with either (a) planar or (b) twisted conformation around rings A and C (see Fig. 1 for ring labeling) and neighbors.

Table 1

Crystal data and statistic refinements for compounds $\mathbf{1}-\mathbf{5}$.

\begin{tabular}{|c|c|c|c|c|c|c|}
\hline & & 1 & 2 & 3 & 4 & 5 \\
\hline \multirow{2}{*}{\multicolumn{2}{|c|}{$\begin{array}{l}\text { Structural formula } \\
\text { fw }(\mathrm{g} / \mathrm{mol})\end{array}$}} & $\mathrm{C}_{20} \mathrm{H}_{19} \mathrm{~N}_{1} \mathrm{O}_{2}$ & $\mathrm{C}_{18} \mathrm{H}_{13} \mathrm{~N}_{1} \mathrm{O}_{4}$ & $\mathrm{C}_{18} \mathrm{H}_{13} \mathrm{Br}_{1} \mathrm{O}_{2}$ & $\mathrm{C}_{18} \mathrm{H}_{14} \mathrm{O}_{3}$ & $\mathrm{C}_{24} \mathrm{H}_{18} \mathrm{O}_{2}$ \\
\hline & & 305.36 & 307.29 & 341.18 & 278.29 & 338.38 \\
\hline \multicolumn{2}{|l|}{ Crystsyst } & monoclinic & orthorhombic & monoclinic & monoclinic & monoclinic \\
\hline \multicolumn{2}{|l|}{ Space group } & $P 2_{1}$ & Pnma & $P 2_{1} / c$ & $P 2_{1} / c$ & $P 2_{1} / c$ \\
\hline \multicolumn{2}{|l|}{$Z / Z^{\prime}$} & $8 / 4$ & $4 / 0.5$ & $8 / 2$ & $8 / 2$ & $4 / 1$ \\
\hline \multicolumn{2}{|l|}{$T(\mathrm{~K})$} & $298(2)$ & $298(2)$ & $298(2)$ & $298(2)$ & $298(2)$ \\
\hline \multirow[t]{4}{*}{ Unit cell dimensions } & $a(\AA)$ & $18.6803(4)$ & $22.5888(6)$ & $17.001(3)$ & $15.0266(4)$ & $16.7703(7)$ \\
\hline & $b(\AA)$ & $6.39240(10)$ & $7.0104(2)$ & $6.0849(10)$ & $5.74850(10)$ & $6.4048(3)$ \\
\hline & $c(\AA)$ & $27.5903(7)$ & $9.6324(3)$ & $30.959(6)$ & $35.5270(9)$ & $16.5680(8)$ \\
\hline & $\beta\left(^{\circ}\right)$ & $90.5934(10)$ & 90 & $113.330(8)$ & $112.320(11)$ & $95.147(3)$ \\
\hline \multicolumn{2}{|c|}{$V\left(\AA^{3}\right)$} & $3294.44(12)$ & $1525.35(8)$ & $2940.8(9)$ & $2838.9(3)$ & $1772.40(14)$ \\
\hline \multicolumn{2}{|c|}{ Calculated density $\left(\mathrm{Mg} / \mathrm{m}^{3}\right)$} & 1.231 & 1.338 & 1.541 & 1.302 & 1.268 \\
\hline \multicolumn{2}{|c|}{ Absorption coefficient $\mu\left(\mathrm{mm}^{-1}\right)$} & 0.079 & 0.096 & 2.797 & 0.088 & 0.079 \\
\hline \multicolumn{2}{|c|}{$\theta$ range for data collection $\left({ }^{\circ}\right)$} & $2.95-25.35$ & $3.42-25.34$ & $3.02-25.65$ & $2.93-25.37$ & $3.31-26.71$ \\
\hline \multirow[t]{3}{*}{ Index ranges } & $h$ & -22 to 22 & -27 to 27 & -20 to 18 & -18 to 18 & -21 to 21 \\
\hline & $k$ & -7 to 7 & -8 to 8 & -7 to 7 & -6 to 6 & -6 to 8 \\
\hline & $l$ & -32 to 33 & -11 to 11 & -37 to 37 & -42 to 42 & -20 to 20 \\
\hline & 37752 & 9773 & 45993 & 25909 & 15878 \\
\hline \multicolumn{2}{|l|}{ unique reflections } & 11762 & 1498 & 5552 & 5153 & 3704 \\
\hline \multicolumn{2}{|c|}{ Symmetry factor $\left(R_{\text {int }}\right)$} & 0.1029 & 0.0444 & 0.0894 & 0.1009 & 0.0821 \\
\hline \multicolumn{2}{|c|}{ Completeness to $\theta_{\max }(\%)$} & 99.2 & 98.5 & 99.5 & 99.2 & 98.5 \\
\hline \multicolumn{2}{|c|}{$F(000)$} & 1296 & 640 & 1376 & 1168 & 712 \\
\hline \multicolumn{2}{|l|}{ parameters refined } & 837 & 135 & 379 & 381 & 235 \\
\hline \multicolumn{2}{|c|}{ Goodness-of-fit on $F^{2}$} & 1.033 & 1.033 & 1.011 & 0.927 & 1.008 \\
\hline \multicolumn{2}{|c|}{ Final $R 1$ factor for $I>2 \sigma(I)$} & 0.0541 & 0.0475 & 0.0342 & 0.0432 & 0.0512 \\
\hline \multicolumn{2}{|c|}{$w R 2$ factor for all data } & 0.1467 & 0.1403 & 0.0842 & 0.1148 & 0.1595 \\
\hline \multicolumn{2}{|c|}{ Largest diff. peak/hole $\left(e / \AA^{3}\right)$} & $0.220 /-0.253$ & $0.118 /-0.163$ & $0.242 /-0.320$ & $0.131 /-0.131$ & $0.249 /-0.214$ \\
\hline \multicolumn{2}{|c|}{ CCDC deposit number } & 1402321 & 1402322 & 1402323 & 1402324 & 1402325 \\
\hline
\end{tabular}


$0.1509 \AA$ A when overlapping molecules 1A to 1D (largest atom deviation of $0.2671 \AA$ for $(16)$. Their conformations are almost completely planar, except for the benzyl moiety (B ring attached to the methylene group according to labeling scheme shown in Fig. 1) twisted by $76.16(8)^{\circ}, 76.94(8)^{\circ}, 78.70(9)^{\circ}$ and $79.44(8)^{\circ}$ in molecules 1A, 1B, 1C and 1D, respectively, from the least-square plane calculated through the non-hydrogen atoms of rings $\mathrm{A}$ and $\mathrm{C}$ (including carbonyl oxygen) and C7. This averaged plane will be hereinafter referred as the molecular mean plane of nostoclide analogues. The RMSD of the thirteen fitted atoms onto the molecular mean plane was $0.0377 \AA$, $0.0555 \AA$, $0.0320 \AA$, $0.0479 \AA$ in molecules 1A1B, 1C and 1D, respectively, with largest atom deviation of $0.0618 \AA$ (C6), $0.0837 \AA$ (C4), $0.0513 \AA$ (C6) and $0.0658 \AA$ (C4), respectively.

The planarity of the ring system involving rings $A$ and $C$ (see Fig. 1 for labeling) can also be associated with the torsional angle C8-C7-C1-C2 (see Table 2) in terms of deviation from 180 or $0^{\circ}$, as discussed in our more recent published article on nostoclide analogues [25]. The $N, N$-dimethylamino group is coplanar with phenyl ring $\mathrm{C}$, as observed in the torsions on the $\mathrm{N} 1-\mathrm{C} 4$ bond axis measuring close to either $0^{\circ}$ or $180^{\circ}$ (Table 2). Thus, this group acts as a $\pi$-electron-donating substituent. This phenomenon can be also observed in the $\mathrm{C}-\mathrm{N}-\mathrm{C}$ valence angles close to $120^{\circ}$ revealing the $s p^{2}$-hybridization of nitrogen (Table 2). In fact, the delocalized resonance seems to be extended over the ring $A$ up to the neighboring unsaturated carbon, $i$. e., the $C_{s p}^{2}-C_{A r}$ bond length is shorter than an expected single-bond distance (this mean value is $1.441(5)$ $\AA$ in compound 1 against 1.47(2) $\AA$, the mean value averaged on 3972 structures deposited in the CSD. This shortening of bond length was also observed for all compounds of the series as consequence of their conjugated para-substituent (Table 2). In addition, the conformation of benzyl moiety is the main responsible for crystallization of compound 1 in the chiral space group $\mathrm{P} 2{ }_{1}$. Taking the molecular mean plane crossing through rings $\mathrm{A}$ and $\mathrm{C}$ and their neighbors as a reference, phenyl ring $B$ lies on the opposite side of lactone oxygens. However, in this structure none of the molecules can be related by mirror symmetry. If they could be related by such symmetry element, the mirror molecules would differ conformationally from those found in the crystal structure reported here by a rotation of $60^{\circ}$ towards the nostoclide mean plane on the bond axis between the $\alpha$-carbon and the methylene one (C10-C12. In other words, there is only one of the two conformations with phenyl ring $\mathrm{C}$ at the equatorial position opposite to the lactone oxygen either above or below the molecular mean plane. Unfortunately, the absolute configuration could not be determined from X-ray crystallographic analysis. This was not possible due to the fact that the most electron-rich atom $(0)$ does not have a large enough anomalous scattering (using MoK $\alpha$ radiation) to allow the determination of reliable Flack parameter with standard uncertainty lower than the safe upper limit of 0.10 .

Compound 2, containing a para-nitro functionality instead of the $\mathrm{N}, \mathrm{N}$-dimethylamino group of compound $\mathbf{1}$, crystallizes with a half of one molecule in the asymmetric unit (Fig. 2). This is due to the location of one molecule on a symmetry element present in the centrosymmetric orthorhombic space group Pnma. Except for phenyl ring $\mathrm{B}$, compound $\mathbf{2}$ is completely planar with all atoms (including methylene carbon C12 and those of phenyl ring B labeled as $\mathrm{C} 13$ and $\mathrm{C} 16)$ sitting on a mirror plane at $(\mathrm{y}, 1 / 2, \mathrm{z})$. In fact, only four atoms are outside the $m$ mirror plane normal to $b$ crystallographic axis and passing through the remaining atoms (C14, C14 ${ }^{\mathrm{i}}, \mathrm{C} 15$, and $\mathrm{C} 15^{\mathrm{i}}$ ). Consequently, these four atoms are normal to the $\mathrm{m}$ mirror plane and the phenyl ring $B$ is also oriented towards opposite side of lactone oxygen in compound 2 , forming an angle of $90.00(5)^{\circ}$ with the molecular plane. Because of these geometric features, compounds $\mathbf{1}$ and $\mathbf{2}$ are, therefore, conformationally similar in terms of the planar fragment formed by the rings $A$ and $C$ and the twist angle of the phenyl ring $B$ in relation to the lactone oxygen present in the planar moiety (Fig. 3). However, compounds $\mathbf{1}$ and $\mathbf{2}$ do slightly differ in terms of a rotation on the bond axis between the C10 $\alpha$-carbon and C12 methylene atoms (Fig. 3). While the syn torsional angle around this bond axis is $0^{\circ}$ in compound $\mathbf{2}$, this value is $25.5(7)^{\circ}$ on average in compound $\mathbf{1}$ (Table 2 ).

Brominated compound $\mathbf{3}$ presents some similarities to compounds $\mathbf{1}$ and $\mathbf{2}$ (Fig. 2). However, the presence of the bromine

Table 2

Selected bond lengths $(\AA)$, valence and torsion angles $\left({ }^{\circ}\right)$ for compounds $\mathbf{1}-\mathbf{5}$.

\begin{tabular}{|c|c|c|c|c|c|c|c|c|c|c|}
\hline Parameter & $1 \mathrm{~A}$ & $1 \mathrm{~B}$ & $1 C$ & $1 \mathrm{D}$ & 2 & $3 \mathrm{~A}$ & $3 B$ & $4 \mathrm{~A}$ & $4 \mathrm{~B}$ & 5 \\
\hline $\mathrm{O} 1-\mathrm{C} 11$ & $1.198(4)$ & $1.199(3)$ & $1.200(4)$ & $1.198(3)$ & $1.197(3)$ & $1.194(3)$ & $1.194(3)$ & $1.208(2)$ & $1.210(2)$ & $1.200(2)$ \\
\hline $\mathrm{O} 2-\mathrm{C} 11$ & $1.383(4)$ & $1.380(3)$ & $1.382(4)$ & $1.386(4)$ & $1.387(3)$ & $1.395(3)$ & $1.398(3)$ & $1.379(2)$ & $1.380(2)$ & $1.386(2)$ \\
\hline $\mathrm{O} 2-\mathrm{C} 8$ & $1.392(3)$ & $1.389(3)$ & $1.393(3)$ & $1.392(3)$ & $1.376(3)$ & $1.385(3)$ & $1.389(3)$ & $1.393(2)$ & $1.399(2)$ & $1.3846(19)$ \\
\hline $\mathrm{X}^{a}-\mathrm{C} 4$ & $1.372(4)$ & $1.379(4)$ & $1.366(4)$ & $1.366(4)$ & $1.465(3)$ & $1.897(2)$ & $1.896(2)$ & $1.362(2)$ & $1.358(2)$ & $1.493(2)$ \\
\hline $\mathrm{C} 1-\mathrm{C} 7$ & $1.443(4)$ & $1.444(4)$ & $1.445(4)$ & $1.433(4)$ & $1.449(3)$ & $1.464(3)$ & $1.457(3)$ & $1.448(2)$ & $1.452(2)$ & $1.450(2)$ \\
\hline $\mathrm{C} 7-\mathrm{C} 8$ & $1.344(4)$ & $1.340(4)$ & $1.341(4)$ & $1.341(4)$ & $1.337(3)$ & $1.338(3)$ & $1.330(3)$ & $1.337(2)$ & $1.329(2)$ & $1.334(2)$ \\
\hline $\mathrm{C} 8-\mathrm{C} 9$ & $1.428(4)$ & $1.431(4)$ & $1.434(4)$ & $1.422(4)$ & $1.448(3)$ & $1.439(3)$ & $1.441(3)$ & $1.436(2)$ & $1.429(2)$ & $1.439(2)$ \\
\hline $\mathrm{C} 9-\mathrm{C} 10$ & $1.331(4)$ & $1.327(4)$ & $1.338(4)$ & $1.336(4)$ & $1.325(3)$ & $1.331(3)$ & $1.330(3)$ & $1.334(2)$ & $1.335(3)$ & $1.331(2)$ \\
\hline C10-C11 & $1.454(4)$ & $1.445(4)$ & $1.454(4)$ & $1.443(4)$ & $1.466(3)$ & $1.465(4)$ & $1.468(3)$ & $1.460(3)$ & $1.456(3)$ & $1.455(2)$ \\
\hline $\mathrm{C} 4-\mathrm{N} 1-\mathrm{C} 19$ & $122.3(3)$ & $121.2(3)$ & $121.7(3)$ & $121.3(3)$ & - & - & - & - & - & - \\
\hline $\mathrm{C} 4-\mathrm{N} 1-\mathrm{C} 20$ & $120.2(3)$ & $120.3(3)$ & $120.8(3)$ & $121.1(3)$ & - & - & - & - & - & - \\
\hline $\mathrm{C} 19-\mathrm{N} 1-\mathrm{C} 20$ & $116.2(3)$ & $117.8(3)$ & $117.1(3)$ & $117.3(3)$ & - & - & - & - & - & - \\
\hline $\mathrm{C} 2-\mathrm{C} 1-\mathrm{C} 7-\mathrm{C} 8$ & $176.1(3)$ & $177.1(3)$ & $177.8(3)$ & $177.6(3)$ & 180 & $162.6(3)$ & $-166.3(3)$ & $175.63(19)$ & $-175.79(19)$ & $-171.90(18)$ \\
\hline $\mathrm{C} 6-\mathrm{C} 1-\mathrm{C} 7-\mathrm{C} 8$ & $-1.4(5)$ & $-0.4(5)$ & $-1.5(5)$ & $0.0(5)$ & 0 & $-16.9(4)$ & $17.7(4)$ & $-3.8(3)$ & $3.8(3)$ & $7.3(3)$ \\
\hline $\mathrm{C} 3-\mathrm{C} 4-\mathrm{N} 1-\mathrm{C} 19$ & $-172.6(3)$ & $-175.1(3)$ & $-174.4(3)$ & $-176.4(3)$ & - & - & - & - & - & - \\
\hline $\mathrm{C} 3-\mathrm{C} 4-\mathrm{N} 1-\mathrm{C} 20$ & $-5.8(4)$ & $-4.7(4)$ & $-2.2(4)$ & $-3.4(5)$ & - & - & - & - & - & - \\
\hline $\mathrm{C} 5-\mathrm{C} 4-\mathrm{N} 1-\mathrm{C} 19$ & $8.3(4)$ & $5.3(4)$ & $5.2(4)$ & $4.2(5)$ & - & - & - & - & - & - \\
\hline $\mathrm{C} 5-\mathrm{C} 4-\mathrm{N} 1-\mathrm{C} 20$ & $175.0(3)$ & $175.7(3)$ & $177.4(3)$ & $177.3(3)$ & - & - & - & - & - & - \\
\hline $\mathrm{C} 9-\mathrm{C} 10-\mathrm{C} 12-\mathrm{C} 13$ & $25.0(5)$ & $24.9(5)$ & $26.4(5)$ & $25.7(5)$ & 0 & $91.3(3)$ & 96.8(3) & $103.9(2)$ & 109.2(2) & $113.5(2)$ \\
\hline $\mathrm{C} 11-\mathrm{C} 10-\mathrm{C} 12-\mathrm{C} 13$ & $-155.3(3)$ & $-155.1(3)$ & $-154.2(3)$ & $-153.2(3)$ & 180 & $-83.7(3)$ & $-80.5(3)$ & $-79.9(2)$ & $-70.9(2)$ & $-66.8(2)$ \\
\hline $\mathrm{C} 10-\mathrm{C} 12-\mathrm{C} 13-\mathrm{C} 14$ & $92.5(3)$ & $95.7(4)$ & 91.3(3) & $93.4(3)$ & $88.95(19)$ & $95.0(3)$ & $94.6(3)$ & $134.2(2)$ & $89.6(2)$ & $116.8(2)$ \\
\hline $\mathrm{C} 10-\mathrm{C} 12-\mathrm{C} 13-\mathrm{C} 18^{b}$ & $-88.1(4)$ & $-85.6(4)$ & $-89.2(4)$ & $-86.7(4)$ & $-88.95(19)$ & $-83.5(3)$ & $-84.0(3)$ & $-49.0(3)$ & $-89.6(2)$ & $-63.9(2)$ \\
\hline
\end{tabular}

a $\mathrm{X}$ is $\mathrm{N} 1$ in compounds 1 and $2, \mathrm{Br} 1$ in compound 3, $\mathrm{O} 3$ in compound 4 and $\mathrm{C} 19$ in compound 5.

b In compound 2, C18 is the mirror image of C14 reflected through the mirror plane at $(\mathrm{y}, 1 / 2, \mathrm{z})$. 
results in some conformational changes when compared to the $\mathrm{N}, \mathrm{N}$-dimethylamino and nitro analogues. Compound 3 crystallizes in the centrosymmetric monoclinic space group $\mathrm{P} 22_{1} / c$ with two molecules in the asymmetric unit (Fig 2). While rings $A$ and $C$ and neighbors are coplanar in $\mathbf{1}$ and $\mathbf{2}$, there is a twisting into this molecular backbone in both crystallographically independent molecules of compound 3. Rings $A$ and $C$ form an angle of $19.46(7)^{\circ}$ and $22.57(7)^{\circ}$ in molecules $\mathbf{3 A}$ and $\mathbf{3 B}$ as a consequence of rotation on the single bond axis between them (see also torsional angle C8-C7-C1-C2 in Table 2). Although these rotations have similar degree values in the two conformers, they occur toward opposite sides of lactone plane (Fig. 3), as can be seen by the similar values of the torsions on the $\mathrm{C} 1-\mathrm{C} 7$ bond axis but with opposite signs (Table 2). These opposite signs are observed when measuring torsions are made on the same enantiomorphs of the conformers, i. e., taken into account if phenyl ring $B$ is in the axial position of bonding to methylene carbon on the same side of the lactone mean plane. Identical enantiomorphs were chosen as asymmetric units for this compound. One can also note that axial position of this ring in compound $\mathbf{3}$ differs from an equatorial one found in compound $\mathbf{1}$ (Fig. 3). Furthermore, ring B is almost perpendicular to lactone mean plane such as in the other two compounds, having an angle between them of $74.55(9)^{\circ}$ and $74.87(8)^{\circ}$ in molecules $\mathbf{3 A}$ and $\mathbf{3 B}$.
A similar benzyl conformation is also observed for compounds 4 and 5, which have a hydroxyl and phenyl group at para-position of ring $\mathrm{C}$, respectively. In compound $\mathbf{4}$, there are two conformers in its asymmetric unit (space group $\mathrm{P} 21 / c$ ) with a planar molecular backbone resembling that of compounds 1 and $\mathbf{2}$ and phenyl ring $\mathrm{B}$ at axial position such as compound 3 (Fig. 3). The RMSD of the thirteen fitted atoms onto the molecular mean plane was $0.0549 \AA$ and $0.0663 \AA$ in molecules $\mathbf{4 A}$ and $\mathbf{4 B}$, with largest atom deviation of $0.106 \AA$ (C6) and $0.102 \AA$ (C3), respectively. This mean plane forms an angle of $72.05(5)^{\circ}$ and $68.38(6)^{\circ}$ with phenyl ring $B$ in these molecules (see also the torsional angle $\mathrm{C} 8-\mathrm{C} 7-\mathrm{C} 1-\mathrm{C} 2$ in Table 2). Nevertheless, these molecules of $\mathbf{4}$ are not superimposable due to rotation on the single bond axis into benzyl group changing the conformation of the phenyl head (see torsion values in Table 2 around the $\mathrm{C} 12-\mathrm{C} 13$ bond between methylene and phenyl carbons).

The molecular backbone of the single molecule in the asymmetric unit of compound $\mathbf{5}$ is also planar, albeit not as planar as noticed for compounds $\mathbf{1}, \mathbf{2}$ and $\mathbf{4}$. The RMSD of $\mathbf{5}$ for its nonhydrogen atoms of the molecular mean plane $(0.0901 \AA$, largest deviation of $0.139 \AA$ for C3) is higher than RMSD values aforementioned for analogues 1, 2 and 4. Moreover, the molecular mean plane of 5 and ring B are twisted by $76.74(5)^{\circ}$, similarly to all other

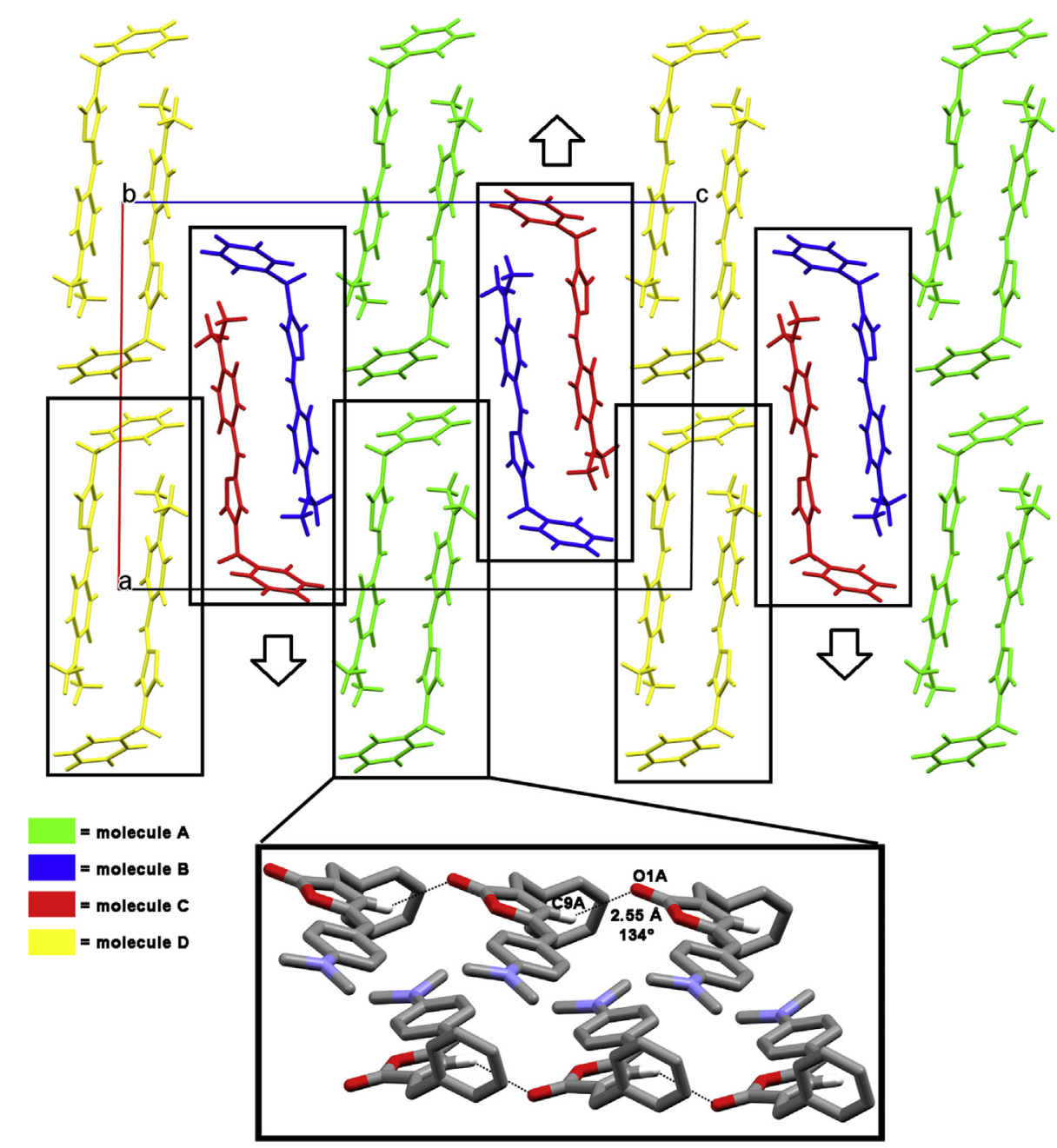

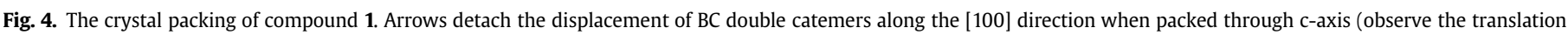

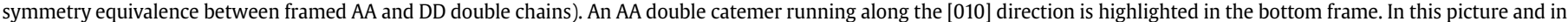

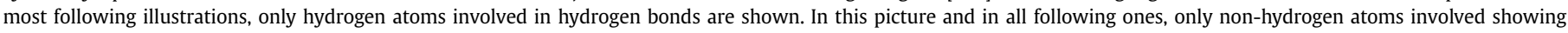
intermolecular contacts are labeled as well as the displayed measurements refer to hydrogen ... acceptor atom (or $C_{g}$ ) distance and hydrogen bonding angle. 


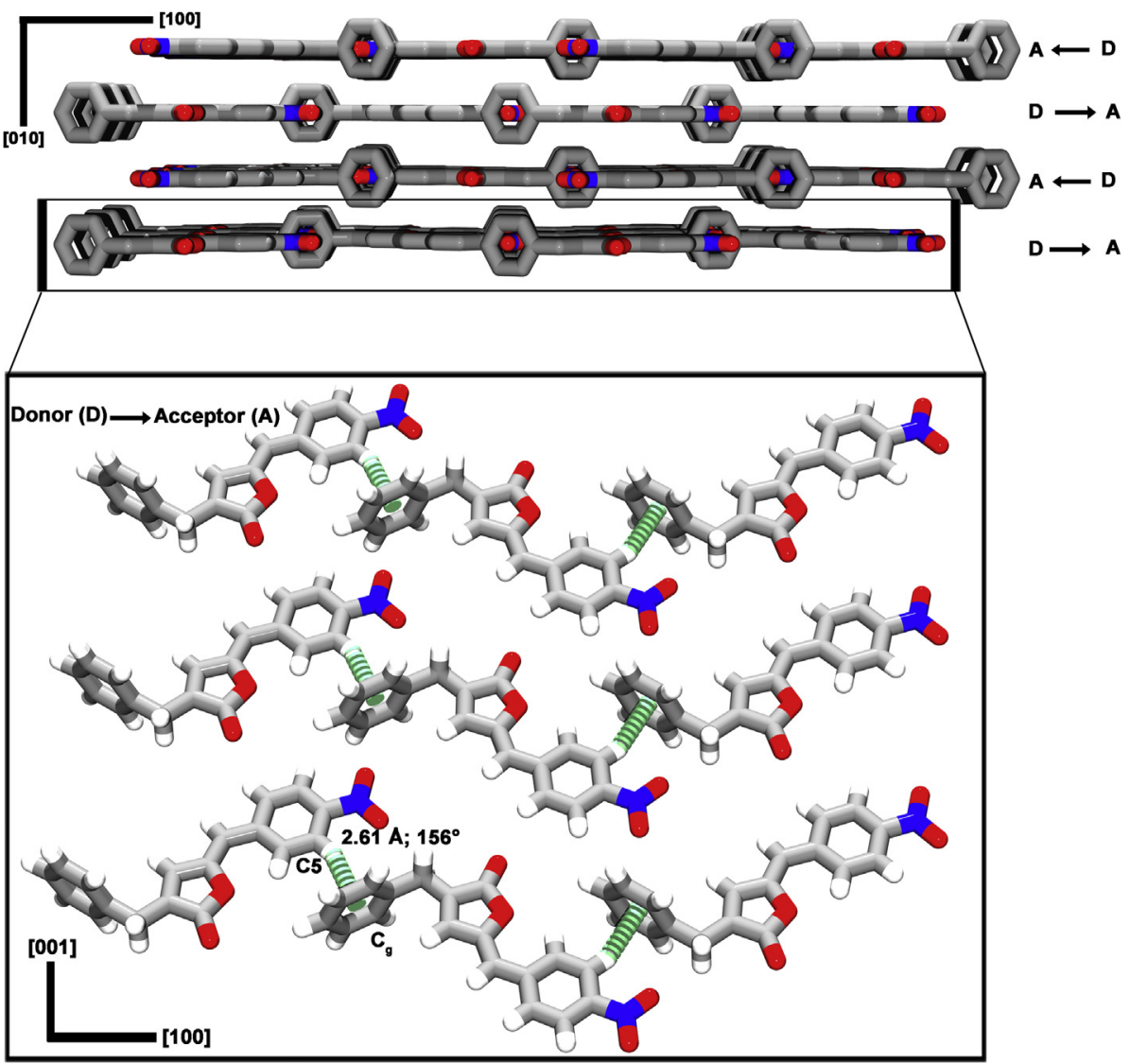

Fig. 5. The layered structure of compound 2. The term $C_{g}$ does refer to centroid calculated through the phenyl ring $C$ carbons.

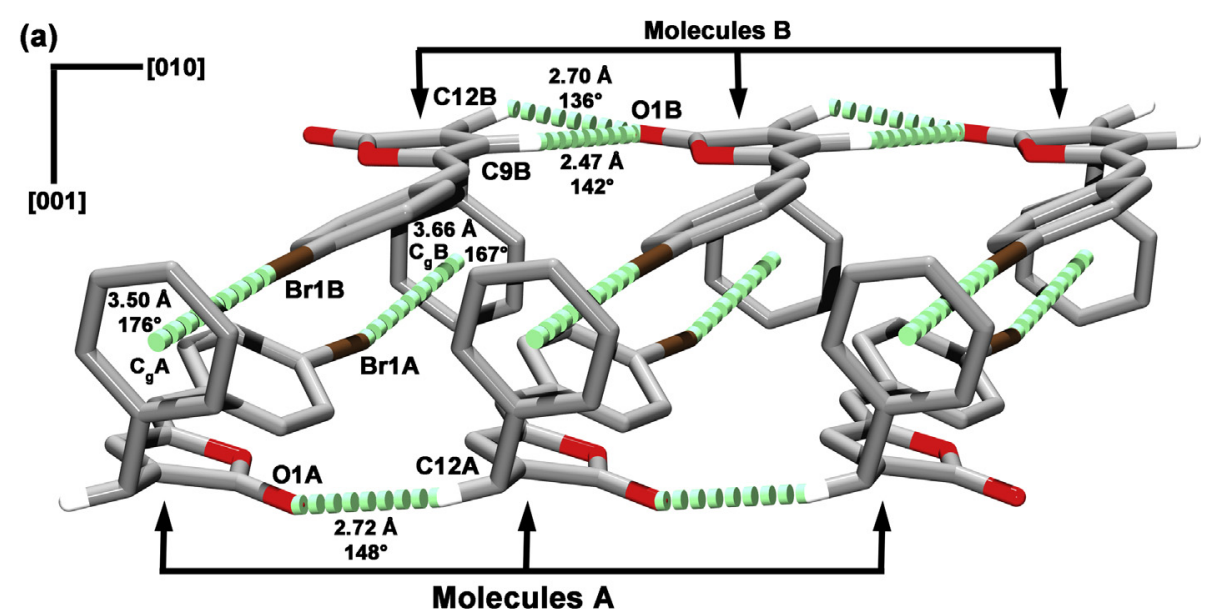

(b)

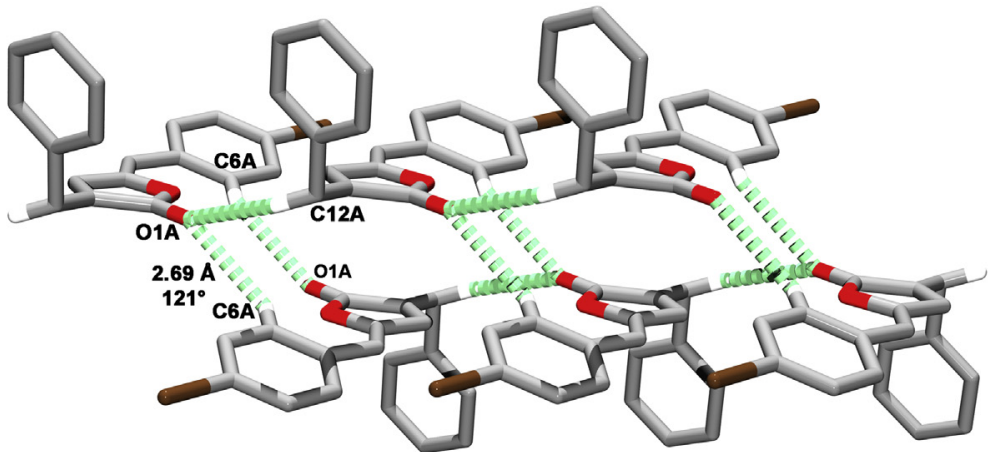

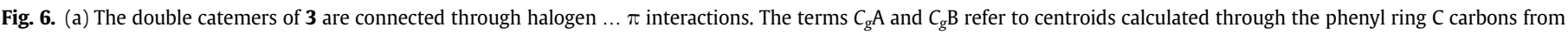
molecules A and B, respectively. (b) Neighboring chains composed by molecules B are interacting through weak non-classical hydrogen bonds. 
analogues (see also the torsional angle $\mathrm{C} 8-\mathrm{C} 7-\mathrm{C} 1-\mathrm{C} 2$ in Table 2). Finally, phenyl rings in the biphenyl moiety are bent by $35.21(6)^{\circ}$.

The crystal packing of compound $\mathbf{1}$ is stabilized through formation of chains assembled parallel to the [010] direction through $\mathrm{C}-\mathrm{H} \cdots \mathrm{O}=\mathrm{C}$ nonclassical hydrogen bonds between lactone moieties from translation-symmetry related molecules (Fig. 4). Therefore, these catemers are composed by a same crystallographically independent molecule. Each chain made up of molecules A and D is face-to-face stacked on top of one another assembled with the same crystallographically independent molecule giving rise to AA and DD double catemer motif. On the other hand, each chain of molecules B is face-to-face stacked on top of one catemer composed by molecules $\mathrm{C}$ (BC double catemer). There are stacking angles of $33.13(5)^{\circ}, 33.18(6)^{\circ}$ and $32.98(5)^{\circ}$ between the molecular mean planes into the AA, DD and $\mathrm{BC}$ double chains, respectively. The double chains of molecules $\mathrm{A}$ or $\mathrm{D}$ are related by translation symmetry along the $c$ axis (Fig. 4). However, their packing along this axis is intercalated by BC double catemer, which are displaced along the $a$-axis when distributed over the $c$-axis. If they were not displaced parallel to the [100] direction, the $c$-axis length would be half of the current one as consequence of translation-symmetry equivalence between $\mathrm{AA}$ and $\mathrm{DD}$ double catemers and between $\mathrm{BC}$ double chains themselves.
Crystal packing of compound $\mathbf{2}$ is marked by the presence of layers assembled with face-to-edge $\mathrm{C}-\mathrm{H} \cdots \pi$ contact between rings $A$ and C (Fig. 5). This interaction gives rise to infinite onedimensional zigzag chains running along the [100] direction. In addition, the molecular layers are stacked along the [010] direction with stacking distances of $3.5 \AA$ Å. Neighboring layers have their catemers growing in opposite directions as shown in top panel of Fig. 5.

The conformerism observed in compound $\mathbf{3}$ can be explained from crystal packing inspection (Fig. 6). In this structure, there are catemers made up of only one conformer growing along the [010] direction. These chains are face-to-face stacked to allow the formation of halogen ... $\pi$ interactions between para-bromine atom and ring $C$. However, the assembly of the chains differs slightly. In the catemer formed by molecules $\mathrm{B}$, lactone mean planes are more aligned than in the chains composed of molecules $A$. These least-square planes are separated by $1.277(18) \AA$ and $0.121(17) \AA$ in the chains of molecules A and B, respectively. Such higher alignment in molecule B catemers is due to bifurcated non-classical $\mathrm{C}-\mathrm{H}$

$\mathrm{O}$ hydrogen bond setting in-plane both lactone and methylene $\mathrm{C}-\mathrm{H}$ donor groups from the same molecule and carbonyl oxygen from a neighbor one. Besides interacting with methylene group in the molecule A chain, this oxygen atom is also an acceptor from

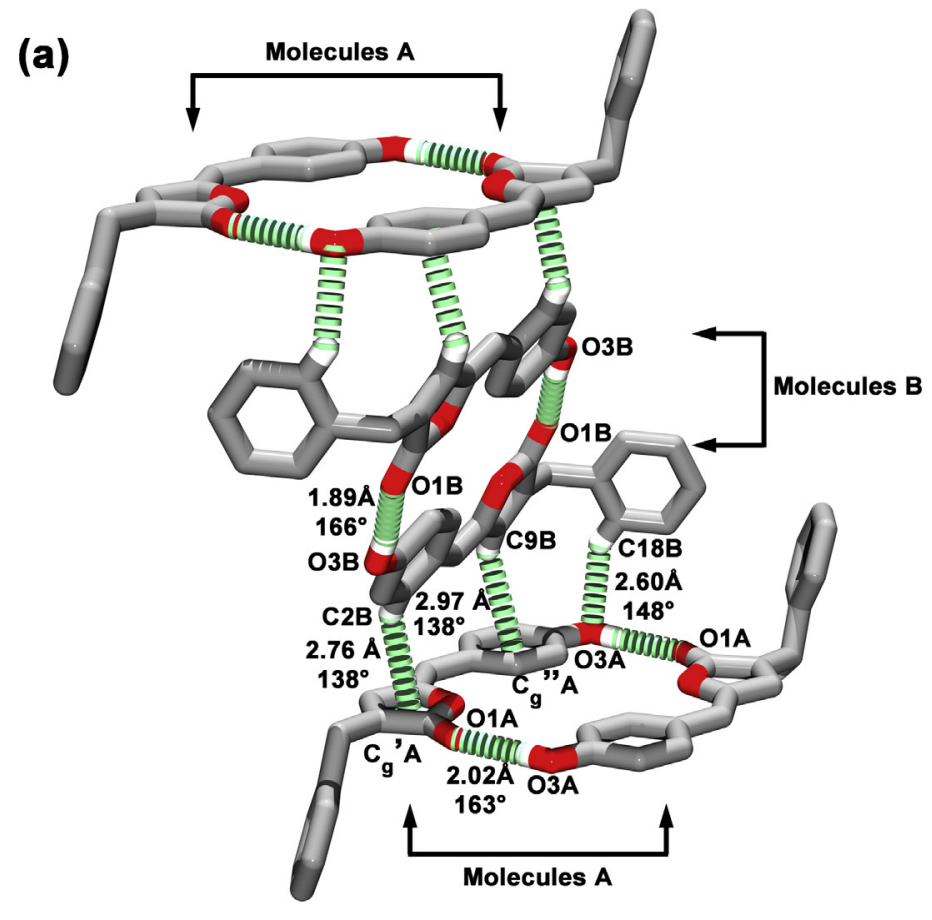

(b)

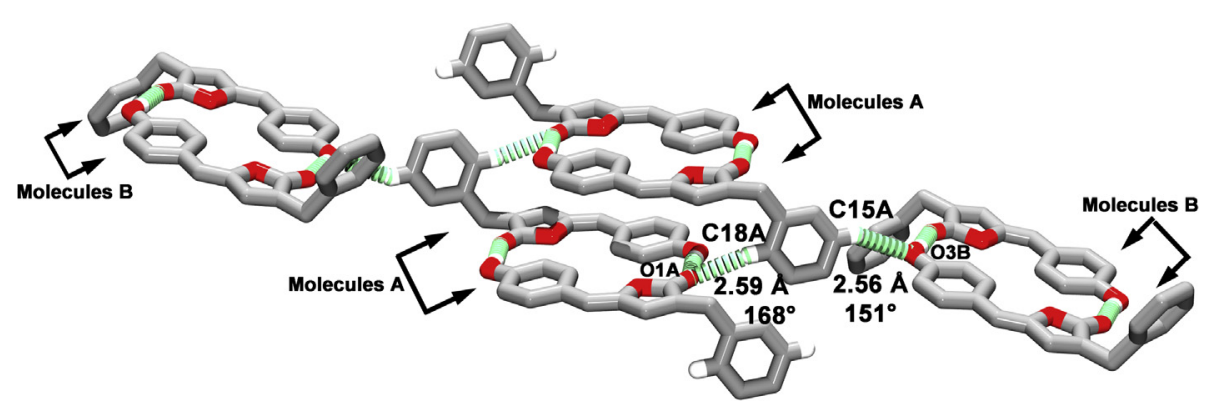

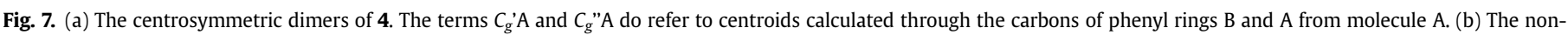
classical hydrogen bonds involving the phenyl ring $\mathrm{C}$ of molecule $\mathrm{A}$. 


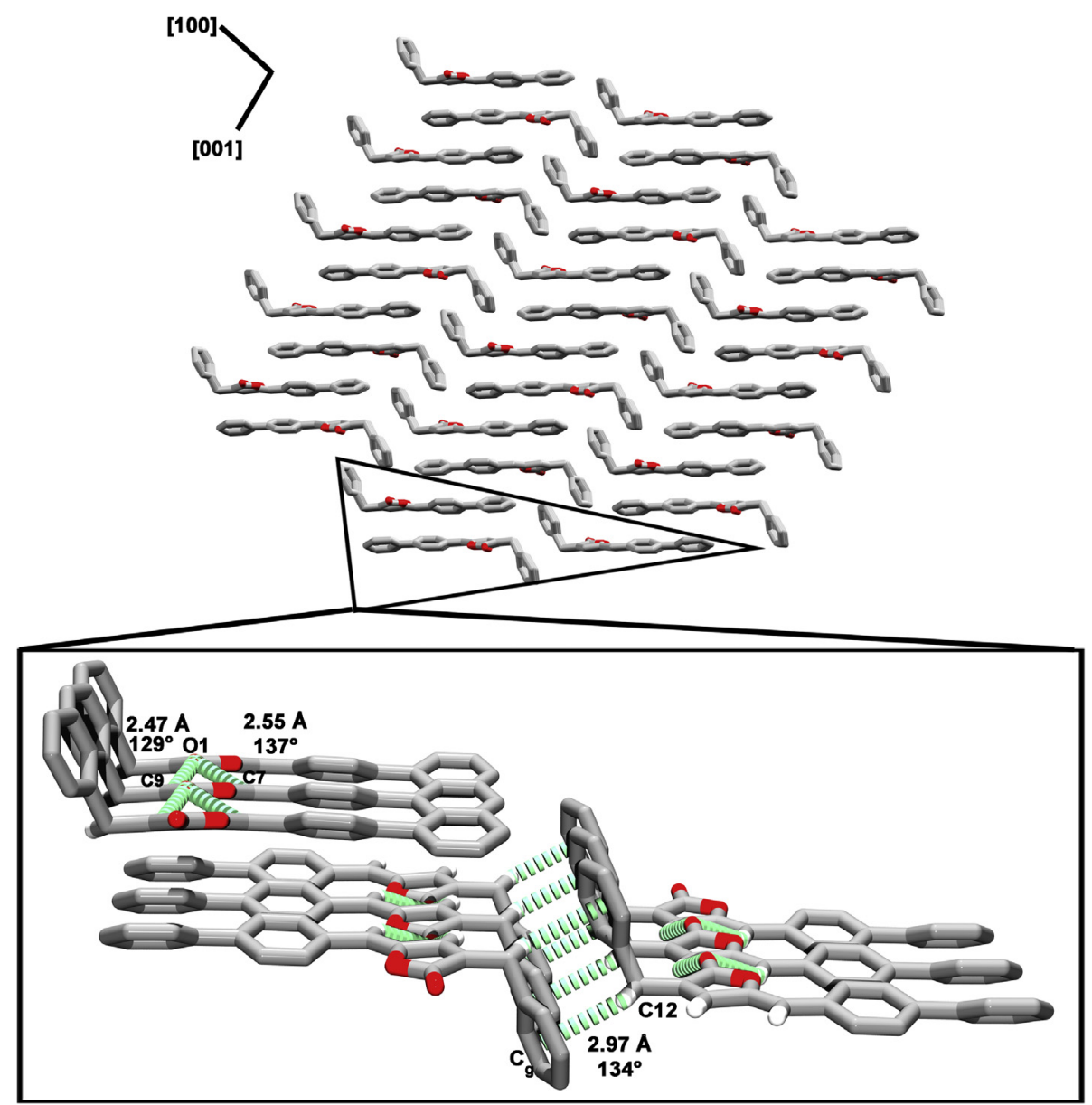

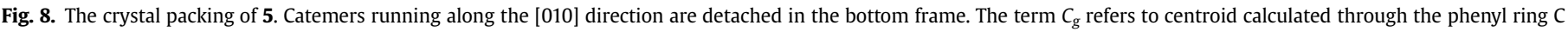
carbons.

phenyl $\mathrm{C}-\mathrm{H}$ moiety from another molecule A stacked on a neighboring catemer (Fig. 6).

Compound $\mathbf{4}$ is the only nostoclide derivative herein described presenting classical intermolecular hydrogen bonds, namely the $\mathrm{O}-\mathrm{H} \ldots \mathrm{O}=\mathrm{C}$ interaction between para-hydroxyl and carbonyl groups. Again, this interaction occurs between molecules of the same conformation, giving rise to centrosymmetric dimers $\mathrm{AA}$ or $\mathrm{BB}$ (Fig. 7). These dimers are connected through face-to-edge $\mathrm{C}-\mathrm{H} \cdots \pi$ interactions in which lactone (C9-H9) and phenyl ring A ( $2-\mathrm{H} 2)$ from molecule $B$ are donors to phenyl rings $A$ and $B$ from molecule $A$. In these interactions, the molecular mean planes form an angle of $63.61(3)^{\circ}$. In this structure, the pattern of weak non-classical hydrogen bonds helps to understand the observed conformerism. Phenyl ring $\mathrm{C}$ from molecule $\mathrm{A}$ is twisted to interact simultaneously as a $\mathrm{C}-\mathrm{H}$ hydrogen bonding donor to carbonyl and hydroxyl oxygen atoms from neighboring molecules A and B (Fig. 7b), respectively, while this phenyl ring from molecule $B$ donates only one hydrogen bonding to hydroxyl oxygen from molecule A (Fig. 7a).

It is noteworthy to mention the role of lactone carbonyl 01 oxygen in the crystal packing of nostoclide analogues. It participates as a bifurcated non-classical hydrogen bonding acceptor in the structure of compound $\mathbf{5}$, being responsible to assemble chains parallel to [010] direction together with olefin $\mathrm{C}-\mathrm{H}$ moieties from lactone ( $\mathrm{C} 9-\mathrm{H} 9)$ and the unsaturated bridge $(\mathrm{C} 7-\mathrm{H} 7)$ as depicted in the frame highlighted in Fig. 8.

These catemers are stacked along the [-101] direction, with a stacking angle between the molecular mean planes of $24.62(3)^{\circ}$. Furthermore, there is $\mathrm{C}-\mathrm{H} \ldots \pi$ contacts between methylene group and phenyl ring $C$ parallel to the [101] completing the threedimensional packing (Fig. 8).

\section{Conclusion}

We have here prepared five new nostoclides analogues and their crystal structures were elucidated. Three compounds exhibit a $Z^{\prime}>1$ value as a result of either conformerism (compounds $\mathbf{3}$ and $\mathbf{4}$, $Z^{\prime}=2$ ) or absence of intermolecular symmetry into the asymmetric unit (compound $\mathbf{1}, Z^{\prime}=4$ ). In the last case, the four crystallographically independent molecules adopt the same conformation while their $\mathrm{C}-\mathrm{H} \ldots \mathrm{O}=\mathrm{C}$ nonclassical hydrogen bonded double catemers are offset packed. Also in the crystal structure of compound 1, there is only one of the two mirror conformations with phenyl ring $\mathrm{B}$ at the equatorial position opposite to the lactone oxygens either above or below the molecular mean plane. This behavior is responsible for its crystallization in the chiral space group $\mathrm{P} 2{ }_{1}$ even though this molecule does not have a stereocenter. The molecular mean plane of nostoclide analogues have been featured by high level of planarity, except in compound 3 that is present in two twisted conformations arising from rotations on the single bond axis between lactone and phenyl rings. Even complete planarity of the molecular backbone onto a mirror plane was observed in compound $\mathbf{2}$. Moreover, the main conformational variability among the compounds studied here is in the benzyl moiety. For instance, the benzyl conformation has been the greatest difference between the two crystallographically independent molecules of compound 4. In their crystal packing, there is 
formation of $-\mathrm{H} \ldots \mathrm{O}=\mathrm{C}$ nonclassical hydrogen bonded double chains in compounds $\mathbf{1}, \mathbf{3}$ and $\mathbf{5}$. Therefore, this double catemer motif is the main supramolecular way to pack nostoclides, although $\mathrm{C}-\mathrm{H} \ldots \pi$ interactions do play an important assembly role in the crystal packing of compounds $\mathbf{2}$ and $\mathbf{5}$. At last, we believe this study will contribute to a better understanding of how substitution pattern does affect the conformation and intermolecular array of nostoclides, besides furnishing their structural knowledge in full detail.

\section{Conflict of interest}

The authors declare that they have no conflict of interest.

\section{Acknowledgments}

The authors are grateful to Conselho Nacional de Desenvolvimento Científico e Tecnológico (Grant No: 304341/2013-4) and Fundação de Amparo à Pesquisa do Estado de Minas Gerais (Grant No: APQ 276/13) for financial support and research fellowships (ACD, FTM, LCAB). The authors express sincere thanks to IFSC-USP and Professor Javier Ellena for the X-ray facilities.

\section{References}

[1] J.N. Blunt, B.R. Copp, R.A. Keyzers, M.H.G. Munro, M.R. Prinsep, Nat. Prod. Rep. 32 (2015) 116-211

[2] D.A. Dias, S. Urban, U. Roessner, Metabolites 2 (2012) 303-336.

[3] Y. Liu, J. Marine, Sci. Res. Dev. 2 (2012) 1-2.

[4] R. Montaser, H. Luesch, Future Med. Chem. 3 (2011) 1475-1489.

[5] A.M.S. Mayer, K.B. Glaser, C. Cuevas, R.S. Jacobs, W. Kem, R.D. Little, J.M. McIntosh, D.J. Newman, B.C. Potts, D.E. Shuster, Trends Pharmacol. Sci. 31 (2010) 255-265.

[6] K.B. Glaser, A.M.S. Mayer, Biochem. Pharmacol. 78 (2009) 440-448.

[7] E. Marris, Nature 443 (2006) 904-905.

[8] B. Haefner, Drug Discov. Today 8 (2003) 536-544.

[9] J. Peng, X. Shen, K.A. El Sayed, D.C. Dunbar, T.L. Perry, S.P. Wikins, M.T. Hamann, S. Bobzin, J. Huesing, R. Camp, M. Prinsen, D. Krupa, M.A. Wideman, J. Agric. Food Chem. 51 (2003) 2246-2252.

[10] S. Boucle, C. Melin, M. Clastre, J. Guilard, Mar. Drugs 13 (2015) 655-665.

[11] M. Sasaki, H. Fuwa, Chem. Rec. 14 (2014) 678-703.

[12] Z.-Y. Yang, H.-Z. Liao, K. Sheng, Y.-F. Chen, Z.-J. Yao, Angew. Chem. Int. Ed. 51 (2012) 6484-6487.
[13] T. Kuranaga, N. Ohtani, R. Tsutsumi, D.G. Baden, J.L.C. Wright, M. Satake, K. Tachibana, Org. Lett. 13 (2011) 696-699.

[14] P.S. Baran, T.J. Maimone, J.M. Richter, Nature 22 (2007) 404-408.

[15] M. Sasaki, H. Fuwa, M. Ishikawa, K. Tachibana, Org. Lett. 1 (1999) 1075-1077.

[16] D.W.C. MacMillan, L.E. Overman, J. Am. Chem. Soc. 117 (1995) 10391-10392.

[17] L.C.A. Barbosa, R.R. Teixeira, G.W. Amarante, Curr. Org. Synth. 12 (2015) $746-771$.

[18] L.C.A. Barbosa, R.R. Teixeira, P.F. Pinheiro, C.R.A. Maltha, A.J. Demuner, Quim. Nova 33 (2010) 1163-1174

[19] X. Yang, Y. Shimizu, J.R. Steiner, J. Clardy, Tetrahedron Lett. 34 (1993) $761-764$.

[20] J. Boukouvalas, F. Maltais, N. Lachance, Tetrahedron Lett. 35 (1994) 7897-7900.

[21] L.C.A. Barbosa, M.E. Rocha, R.R. Teixeira, C.R.A. Maltha, G. Forlani, J. Agric. Food Chem. 55 (2007) 8562-8569.

[22] R.R. Teixeira, L.C.A. Barbosa, G. Forlani, D.P. Veloso, J.W.M. Carneiro, J. Agric Food. Chem. 56 (2008) 2321-2329.

[23] L.C.A. Barbosa, A.J. Demuner, C.R.A. Maltha, R.R. Teixeira, K.A.P. Souza, K.U. Bicalho, Z. Naturforsch 64b (2009) 245-251.

[24] L.C.A. Barbosa, J.O.S. Varejão, D. Petrollino, P.F. Pinheiro, A.J. Demuner, C.R.A. Maltha, G. Forlani, Arkivoc iv (2012) 15-32.

[25] R.R. Teixeira, P.F. Pinheiro, L.C.A. Barbosa, J.W. Carneiro, G. Forlani, Pest. Manag. Sci. 66 (2010) 196-202.

[26] R.R. Teixeira, L.C.A. Barbosa, J.O.S. Varejão, D.P. Veloso, J. Ellena, A.C. Doriguetto, M.G.B. Drew, F.M.D. Ismail, J. Mol. Struct. 837 (2007) $197-205$.

[27] R.R. Teixeira, L.C.A. Barbosa, J.W.M. Carneiro, R.S. Corrêa, J. Ellena, A.C. Doriguetto, J. Mol. Struct. 917 (2009) 1-9.

[28] R.R. Texeira, L.C.A. Barbosa, M.A. Kabeshov, C.R.A. Maltha, R.S. Corrêa, A.C. Doriguetto, J. Mol. Struct. 1075 (2014) 53-62.

[29] X. Jusseau, L. Chabaud, C. Guilou, Tetrahedron 70 (2014) 2595-2615.

[30] G. Casiraghi, L. Battistini, C. Curti, G. Rassu, F. Zanardi, Chem. Rev. 111 (2011) 3076-3154.

[31] C.W. Jefford, D. Jaggi, J. Boukouvalas, Tetrahedron Lett. 28 (1987) 4037-4040.

[32] Bruker -Nonius, Kappa CCD Reference Manual, 1998. Nonius B.V., P.O. Box 811, 2600 Av, Delft, The Netherlands.

[33] Nonius, COLLECT. Nonius BV, Delft, The Netherlands, 1999.

[34] Z. Otwinowski, W. Minor, in: C.W. Carter Jr., R.M. Sweet (Eds.), Methods in Enzymology, Macromolecular Crystallography Part a, vol. 276, Academic Press, New York, 1997, pp. 307-326.

[35] G.M. Sheldrick, Acta Cryst. A64 (2008) 112-122.

[36] P.R. Edgington, P. McCabe, C.F. Macrae, E. Pidcock, G.P. Shields, R. Taylor, M. Towler, J. van de Streek, J. Appl. Cryst. 39 (2006) 453-457.

[37] L.J. Farrugia, J. Appl. Cryst. 30 (1997) 565.

[38] L.J. Farrugia, J. Appl. Cryst. 32 (1999) 837-838.

[39] I.J. Bruno, J.C. Cole, M. Kessler, J. Luo, W.D.S. Motherwell, L.H. Purkis, B.R. Smith, R. Taylor, R.I. Cooper, S.E. Harris, A.G. Orpen, J. Chem. Inf. Comput. Sci. 44 (2004) 2133-2144.

[40] F.H. Allen, Acta Cryst. B58 (2002) 380-388. 